\title{
Evolving a Thermostable DNA Polymerase That Amplifies from Highly Damaged Templates**
}

\author{
Christian Gloeckner, Katharina B. M. Sauter, and Andreas Marx*
}

DNA is the fundamental material that stores and passes genetic information from one generation to the next. How ever, DNA is subject to spontaneous hydrolysis of the phosphodiester, $N$ glycosidic, and amino bonds, and DNA is exposed to constant attack by oxygen based free radicals that damage the nucleobases and sugar backbone as well as to ultraviolet (UV) light. ${ }^{[1]}$ The resulting DNA lesions present a significant block for the replication machinery, and it has long been unclear how cells perform DNA synthesis past these lesions. Only recently, novel specialized DNA polymerases have been identified that are involved in translesion syn thesis. ${ }^{[2]}$ These enzymes are found in a variety of organisms and are involved, for example, in the suppression of skin cancer in humans. ${ }^{[2]}$ Despite intensive structural and func tional investigations, the mechanistic basis of the proficiency of some DNA polymerases to bypass certain lesions is not yet fully understood. To gain new insights into the observed different substrate tolerance displayed by DNA polymerases, we intended to develop a DNA polymerase displaying lesion bypass activity from one originally deficient in this property.

Methods of directed evolution have been shown to be suitable to engineer nucleic acid polymerases with altered properties. ${ }^{[3]}$ Alterations were mainly achieved by directed molecular evolution using genetic complementation and/or screening ${ }^{[4]}$ phage display, ${ }^{[5]}$ and in vitro compartmentaliza tion. ${ }^{[6]}$ Herein, we show that the described lesion bypass proficient DNA polymerase variant can be identified by screening of a small library of mutated enzymes that are obtained through random (nonfocused) mutagenesis. In contrast to the wild type enzyme, the obtained mutant can be used to amplify DNA by polymerase chain reaction (PCR) from damaged DNA. The new DNA polymerase may be suitable for analysis in forensics or in studies of "ancient" DNA where amplification from damaged DNA has been reported to be problematic. ${ }^{[7]}$

To evolve a DNA polymerase that is able to bypass DNA lesions, we screened a previously described library of $\mathrm{N}$ terminal shortened forms of the DNA polymerase from Thermus aquaticus (Klentaq), ${ }^{[8]}$ which was obtained by

[*] Dipl. Biol. C. Gloeckner, Dipl. Chem. K. B. M. Sauter,

Prof. Dr. A. Marx

Department of Chemistry

Universität Konstanz

78457 Konstanz (Germany)

Fax: $(+49) 7531885140$

E mail: andreas.marx@uni konstanz.de

[**] We gratefully acknowledge funding by the DFG.

$\square$ Supporting information for this article is available on the WWW under http://www.angewandte.org or from the author. error prone PCR. ${ }^{[4]}$ The library contains about 1000 PCR active Klentaq variants. We employed a screening approach based on primer extension and detection of the resulting double stranded DNA by SYBRgreenI using automated liquid handling. ${ }^{[\mathrm{e}]}$ All reactions were conducted in parallel in 384 well format plates and analyzed employing a standard microplate reader. Processive DNA polymerases like Klentaq are known to incorporate a nucleotide opposite a lesion and extend from the lesion with significantly lower efficiencies than those with undamaged DNA. ${ }^{[2]}$ Thus, to mimic lesion bypass in the screening setup we chose to investigate primer extension in the presence of only three dNTPs (exclusion of dATP) even though the employed template calls for all four dNTPs (see the Supporting Information). Similar to lesion bypass, misincorporation and extension of the formed mis matches are known to significantly hamper efficient enzy matic DNA synthesis as well. ${ }^{[\mathrm{b}, 9]}$

After screening the library we identified one DNA polymerase mutant that exhibited promising properties. The enzyme was subsequently purified to homogeneity and further characterized. Sequencing revealed that the identified enzyme contained a single mutation (Met747Lys); we refer to the enzyme as M747K in the following discussion. ${ }^{[10]} \mathrm{Next}$, we functionally characterized the new enzyme in comparison to the wild type. First, we performed primer extensions in the absence of one dNTP, the setup employed in the screening (see Figure 1). In cases where one dNTP was missing both DNA polymerases are able to extend the primer to a limited extent. However, M747K is able to generate significantly longer reaction products than those of the wild type under identical reaction conditions. These results should be expected if the screening was indeed successful. They further suggest that M747K has increased propensity for misincorpo ration and mismatch extension and thus a reduced selectivity.

To quantify the selectivity of the mutant in comparison to that of the wild type, we determined the error spectrum of both enzymes employing a reported PCR based assay (see the Supporting Information). ${ }^{[4]}$ The wild type enzyme exhib ited an error rate of $8.8 \times 10^{-5}$, which is on the same order of that reported before. ${ }^{[4 b]}$ Interestingly, the mutant exhibited a similar error rate of $11.5 \times 10^{-5}$. To further investigate the fidelity of the mutant enzyme, we performed quantitative studies of misinsertion and mismatch extension by measuring the steady state kinetic parameters (see the Supporting Information). We found the wild type and mutant enzymes to have similar fidelities; thus, the results obtained by the PCR based fidelity assay were further corroborated.

Next, we investigated the lesion bypass ability of M747K in comparison to that of the wild type by employing templates that contain site specifically introduced lesions (Figure 2). We 


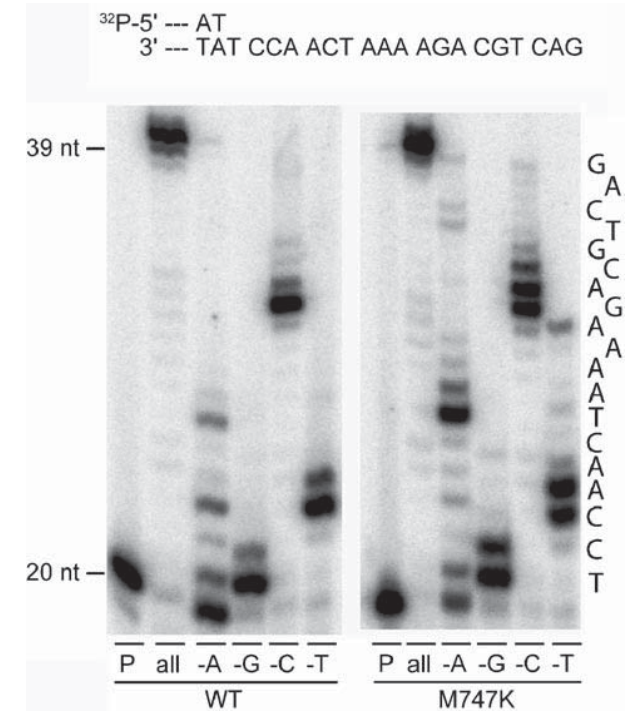

Figure 1. DNA synthesis in the absence of one canonical dNTP. $5^{\prime 32} \mathrm{P}$ labeled primer template complex (sequences as indicated) were incubated with equally high amounts of DNA polymerase (wild type (WT) and mutant M747K, respectively) comprising varied combina tions of dNTPs. P: primer alone; all: all four dNTPs; $N$ : reaction was performed in the absence of the indicated dNTP but with the remaining three dNTP in equal amounts. For details see the Support ing Information.

studied the effects on a stabilized abasic site (AP) that mimics lesions derived from cleavage of the glycosidic bond, and on prominent purine lesions that are generated through oxida tion ( 8 oxoadenine and guanine). These lesions were known a)

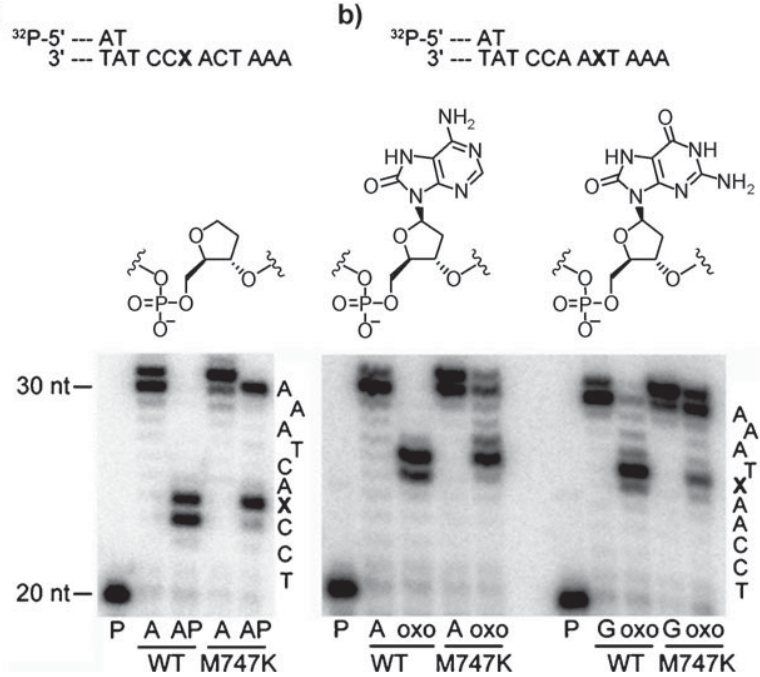

Figure 2. DNA synthesis with lesion bypass. a) Experiments with the stabilized abasic site (AP). $5^{\prime 32} \mathrm{P}$ labeled primer template complexes (sequence as indicated) were incubated with equally high amounts of DNA polymerase (wild type (WT) and mutant M747K, respectively) and all four dNTPs. $P$ : primer alone; $A$ : template containing a $d A$ residue at position marked with an $\mathbf{X}$; AP: template containing a lesion at the position marked with an $\mathbf{X}$. b) Experiments with oxidized purines. Reactions were conducted as described for (a) with the exception that oxidized lesions were introduced at the indicated positions. For details see the Supporting Information. to represent significant blockage for proceeding enzymatic DNA synthesis. ${ }^{[2,11]}$ We found that both enzymes are able to fully extend the primer strand when nondamaged templates were provided (Figure 2, lanes A and G).

Indeed, further characterization indicates that the wild type enzyme and M747K have similar specific activities with nondamaged DNA (see Supporting Information). However, when the templates contained damaged sites the two enzymes behaved differently. While the wild type enzyme pauses before and after incorporation opposite the damaged site, M747K is clearly more active and bypasses the lesions to a significantly increased extent (Figure 2). Quantitative inves tigations of the action of the two enzymes on the abasic site analogue (see the Supporting Information) indicate that both incorporate preferentially dA moieties opposite this damaged site to almost equal steady state efficiencies. However, extension from primer strands bearing an abasic site ana logue moiety is about sevenfold more efficiently promoted by the M747K mutant than by the wild type enzyme.

Next, we investigated the ability of mutant M747K to process DNA that has been damaged through irradiation with UV light $(\lambda=254 \mathrm{~nm})$. First we irradiated a double stranded DNA plasmid at varied doses (see the Supporting Informa tion). Agarose gel analysis of the irradiation products indi cated significant light dependent damage of the plasmid (Figure $3 \mathrm{a}$ ). The damaged DNA was subsequently employed as template for PCR amplification of an approximately $1.8 \mathrm{~kb}$ DNA fragment. All reactions were conducted without any optimization in the buffer originally described for Klentaq. ${ }^{[8]}$

a)

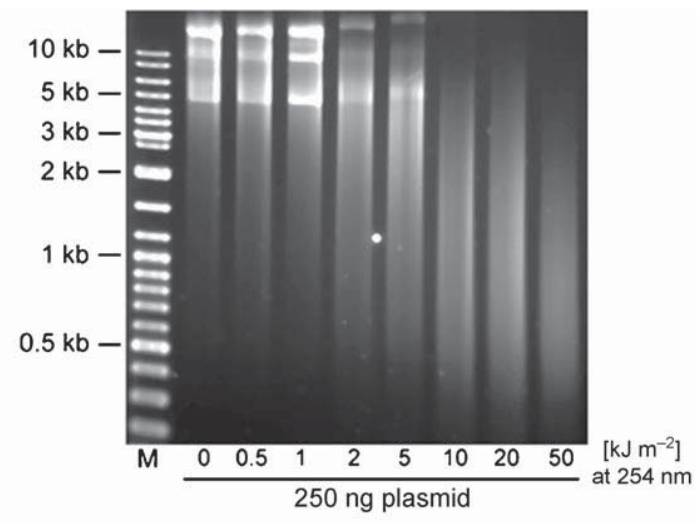

b)

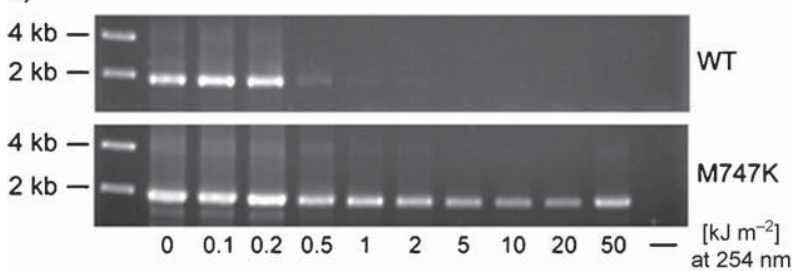

Figure 3. Generation of UV damaged DNA and PCR amplification. a) Irradiation of double stranded plasmid DNA with UV light in varying doses. b) PCR amplification of an approximately $1.8 \mathrm{~kb}$ fragment using the UV damaged DNA as the template. For all reactions identical conditions were employed in PCR. Left lane: DNA marker; right lane: PCR performed in the absence of target DNA. Analysis was performed by agarose gel electrophoresis and ethidium bromide staining. For details see the Supporting Information. 
When the wild type enzyme was used, no significant PCR amplification was observed for DNA irradiated at doses of $0.5 \mathrm{~kJ} \mathrm{~m}^{-12}$ or higher (Figure $3 \mathrm{~b}$ ). Strikingly, M747K was clearly capable of amplifying DNA even from targets that were irradiated at significantly higher doses (Figure $3 \mathrm{~b}$ ). Interestingly, partial sequencing of the PCR amplification products conducted by a commercial supplier showed that M747K is able to process the damaged DNA with sufficiently high sequence selectivity enabling the determination of the original sequence of the target (see the Supporting Informa tion).

In summary, by screening a library of arbitrary random ized mutants, we have identified a DNA polymerase that is able to bypass DNA lesions significantly more efficiently than the parental enzyme. In fact, the mutant is able to use DNA that was damaged by UV light as a target for PCR amplification, a feature the wild type enzyme is lacking. Interestingly, a similar approach was taken by Holliger et al. for evolution of a DNA polymerase by compartmentalized self replication. ${ }^{[6 b]}$ It was reported that searching for an enzyme variant with increased ability to extend mismatched primer termini led to a DNA polymerase with a broader ability to use modified substrates.

Our mutant contains a single hydrophilic substitution (lysine) at position M747. Inspection of the crystal structure of Klentaq complexed with its DNA substrate ${ }^{[12]}$ indicates that this residue contacts the $2^{\prime}$ deoxyribose moiety of the first base pair in the template strand. Interestingly, by employing a directed evolutionary approach, Jestin et al. have recently identified the same mutation in combination with an addi tional mutation to enable the respective enzyme (M747K, E742K) to use RNA as a template for DNA synthesis. ${ }^{[5 d]}$ These findings justify further investigation of the involvement of this position in enzyme function.

Recently, a new group of natural DNA polymerases was discovered that harbor lesion bypass activity and are also characterized by relatively low specific activity and selectivity in processing nondamaged templates. ${ }^{[2]}$ In contrast, our evolved DNA polymerase is particularly interesting since it exhibits the features of high activity and selectivity in combination with lesion bypass propensity in one enzyme. Particularly, the propensity to process highly damaged DNA templates in PCR amplification may be useful for forensic applications and the amplification of "ancient" DNA. ${ }^{[7,13]} \mathrm{We}$ are currently pursuing functional and structural studies that should shed more light on the origin of the observed effects.

Keywords: directed evolution - DNA damage - DNA polymerase . polymerase chain reaction

[1] Recent reviews: a) H. A. Wagenknecht, Angew. Chem. 2006 118, 5709 5711; Angew. Chem. Int. Ed. 2006, 45, 5583 5585; b) T. Carell, L. T. Burgdorf, L. M. Kundu, M. Cichon, Curr. Opin. Chem. Biol. 2001, 5, 491 498; c) E. C. Friedberg, G. C. Walker, W. Siede, DNA Repair and Mutagenesis, American Society for Microbiology Press, Washington, DC, 1995; d) O. D. Schärer, Angew. Chem. 2003, 115, 3052 3082; Angew. Chem. Int. Ed. 2003, 42, 29462974.

[2] Recent reviews: a) S. Prakash, R. E. Johnson, L. Prakash, Annu. Rev. Biochem. 2005, 74, 317 353; b) M. F. Goodman, Аnnu. Rev. Biochem. 2002, 71, 17 50; c) U. Hübscher, G. Maga, S. Spadari, Annu. Rev. Biochem. 2002, 71, 133 163; d) A. Marx, D. Summerer, ChemBioChem 2002, 3, 405407.

[3] Reviews: a) A. A. Henry, F. E. Romesberg, Curr. Opin. Bio technol. 2005, 16, 370 377; b) S. Brakmann, Cell. Mol. Life Sci. 2005, 62, 2634 2646; c) J. F. Davidson, J. Anderson, H. Guo, D. Landis, L. A. Loeb in Directed Molecular Evolution of Proteins (Eds.: S. Brakmann, K. Johnsson), Wiley VCH, Weinheim, 2002, pp. 281307.

[4] a) P. H. Patel, L. A. Loeb, J. Biol. Chem. 2000, 275, 40266 40272; b) P. H. Patel, H. Kawate, E. Adman, M. Ashbach, L. A. Loeb, J. Biol. Chem. 2001, 276, 5044 5051; c) S. Brak mann, S. Grzeszik, ChemBioChem 2001, 2, 212 219; d) M. B. Kermekchiev, A. Tzekov, W. M. Barnes, Nucleic Acids Res. 2003, 31, 6139 6147; e) D. Summerer, N. Z. Rudinger, I. Detmer, A. Marx, Angew. Chem. 2005, 117, 4791 4794; Angew. Chem. Int. Ed. 2005, 44, 4712 4715; ; f) K. B. M. Sauter, A. Marx, Angew. Chem. 2006, 118, 7795 7797; Angew. Chem. Int. Ed. 2006, 45, 7633 7635; g) M. Strerath, C. Gloeckner, D. Liu, A. Schnur, A. Marx, ChemBioChem 2007, 8, 395401.

[5] a) M. Fa, A. Radeghieri, A. A. Henry, F. E. Romesberg, J. Am. Chem. Soc. 2004, 126, 1748 1754; b) A. M. Leconte, L. Chen, F. E. Romesberg, J. Am. Chem. Soc. 2005, 127, 12470 12471; c) G. Xia, L. Chen, T. Sera, M. Fa, P. G. Schultz, F. E. Romes berg, Proc. Natl. Acad. Sci. USA 2002, 99, 6597 6602; d) S. Vichier Guerre, S. Ferris, N. Auberger, K. Mahiddine, J. L. Jestin, Angew. Chem. 2006, 118, 6279 6283; Angew. Chem. Int. Ed. 2006, 45, 61336137.

[6] a) F. J. Ghadessy, J. L. Ong, P. Holliger, Proc. Natl. Acad. Sci. USA 2001, 98, 4552 4557; b) F. J. Ghadessy, N. Ramsay, F. Boudsocq, D. Loakes, A. Brown, S. Iwai, A. Vaisman, R. Woodgate, P. Holliger, Nat. Biotechnol. 2004, 22, 755 759; c) J. L. Ong, D. Loakes, S. Jaroslawski, K. Too, P. Holliger, J. Mol. Biol. 2006, 361, 537550 .

[7] For example: M. Stiller, R. E. Green, M. Ronan, J. F. Simons, L. Du, W. He, M. Egholm, J. Rothberg, S. G. Keats, N. D. Ovodov, E. E. Antipina, G. F. Baryshnikov, Y. V. Kuzmin, A. A. Vasilev ski, G. E. Wuenschell, J. Termini, M. Hofreiter, V. Jaenicke Després, S. Pääbo, Proc. Natl. Acad. Sci. USA 2006, 103, 13578 13584 , and references therein.

[8] W. M. Barnes, Gene 1992, 112, 2935

[9] a) T. A. Kunkel, J. Biol. Chem. 2004, 279, 16895 16898; b) T. A. Kunkel, K. Bebenek, Annu. Rev. Biochem. 2000, 69, 497529.

[10] Numbering according to the sequence of full length Thermus aquaticus DNA polymerase was employed.

[11] R. E. Wellinger, F. Thoma, Nucleic Acids Res. 1996, 24, 1578 1579.

[12] a) Y. Li, V. Mitaxov, G. Waksman, Proc. Natl. Acad. Sci. USA 1999, 96, 9491 9496; b) Y. Li, S. Korolev, G. Waksman, EMBO J. 1998, 17, 75147525 .

[13] Amplification of damaged DNA was previously reported using a blend of several DNA polymerases: J. P. McDonald, A. Hall, D. Gasparuttto, J. Cadet, J. Ballantyne, R. Woodgate, Nucleic Acids Res. 2006, 34, 11021111. 